\title{
Similarity Solution of Marangoni Convection Boundary Layer Flow over a Flat Surface in a Nanofluid
}

\author{
Norihan Md. Arifin, ${ }^{1}$ Roslinda Nazar, ${ }^{2}$ and Ioan Pop ${ }^{3}$ \\ ${ }^{1}$ Institute for Mathematical Research and Department of Mathematics, Universiti Putra Malaysia, 43400 Serdang, \\ Selangor, Malaysia \\ ${ }^{2}$ School of Mathematical Sciences, Faculty of Science \& Technology, Universiti Kebangsaan Malaysia, 43600 Bangi, \\ Selangor, Malaysia \\ ${ }^{3}$ Department of Mathematics, Babeş-Bolyai University, 400084 Cluj-Napoca, Romania
}

Correspondence should be addressed to Norihan Md. Arifin; norihanarifin@yahoo.com

Received 21 June 2013; Accepted 10 December 2013

Academic Editor: Mohamed Fathy El-Amin

Copyright (C) 2013 Norihan Md. Arifin et al. This is an open access article distributed under the Creative Commons Attribution License, which permits unrestricted use, distribution, and reproduction in any medium, provided the original work is properly cited.

The problem of steady Marangoni boundary layer flow and heat transfer over a flat plate in a nanofluid is studied using different types of nanoparticles. The general governing partial differential equations are transformed into a set of two nonlinear ordinary differential equations using unique similarity transformation. Numerical solutions of the similarity equations are obtained using the Runge-Kutta-Fehlberg (RKF) method. Three different types of nanoparticles are considered, namely, $\mathrm{Cu}, \mathrm{Al}_{2} \mathrm{O}_{3}$, and $\mathrm{TiO}_{2}$, by using water as a base fluid with Prandtl number $\operatorname{Pr}=6.2$. The effects of the nanoparticle volume fraction $\phi$ and the constant exponent $m$ on the flow and heat transfer characteristics are obtained and discussed.

\section{Introduction}

A nanofluid is a colloidal mixture of nanosized particles $(<100 \mathrm{~nm})$ in a base fluid. It is known that nanofluid can tremendously enhance the heat transfer characteristics of the original (base) fluid. One such characteristic of nanofluid is the anomalous high thermal conductivity at very low concentration of nanoparticles and the considerable enhancement of convective heat transfer. Thus, nanofluids have many applications in industry such as coolants, lubricants, heat exchangers, and microchannel heat sinks. Nanoparticles are made of various materials such as oxide ceramics, and nitride ceramics. The objective of nanofluids is to achieve the best possible thermal properties with the least possible $(<1 \%)$ volume fraction of nanoparticles in the base fluid [1]. There have been many studies in the literature to better understand the mechanism behind the enhanced heat transfer characteristics. An excellent collection of papers on this topic can be found in the book by Das et al. [2] and in several review papers ([3-8]). There are also several experimental studies to better understand the mechanism of heat transfer enhancement for natural convection heat transfer in nanofluids $([1,9-12])$.

Marangoni flow induced by surface tension along a liquid surface causes undesirable effects in crystal growth melts in the same manner as buoyancy-induced natural convection [13]. These undesirable effects also occur in space-based crystal growth experiments since Marangoni flow is involved in microgravity as well as in earth gravity. An excellent view of the Marangoni effect from the perspective of all three possible interfaces as motion inducing agents has been done by Tadmor [14]. It is worth mentioning that there are two existing models for Marangoni boundary layer that have been studied, namely, model for nonisobaric Marangoni boundary layer as discussed by Golia and Viviani [15] and model for Marangoni boundary layer over a flat plate studied by Christopher and Wang [13]. Marangoni boundary layer studied by Golia and Viviani [15] has been extended by Pop et al. [16] where they included the concentration equation. Chamkha et al. [17] studied the same model with Golia and Viviani [15] in which they considered the gravity effects. Hamid et al. [18] extended the problem of the thermosolutal 
Marangoni forced convection boundary layer flow by Pop et al. [16] when the wall is permeable. Very recently, Mat el al. [19] discussed the radiation effects on the problem of Marangoni boundary layer with permeable surface. On the other hand, nanofluid equations model as proposed by Tiwari and Das [20] has been used by Arifin et al. [21] for the Marangoni boundary layer problem by Golia and Viviani [15]. They found that the numerical results also indicate that, for both a regular fluid $(\varphi=0)$ and a nanofluid $(\varphi \neq 0)$, dual solutions exist when $\beta<0.5$. These dual solutions were not discussed by Golia and Viviani [15]. This problem has been extended by Remeli et al. [22] to the problem with suction and injection effects. Mat et al. [23] also extended the problem of Marangoni boundary layer in a nanofluid by Arifin et al. [21] to the radiation effect.

It is worth mentioning that Christopher and Wang [13] considered the Marangoni boundary layer over a flat plate where the term $u_{e}(x)$, which is the velocity of the external flow in Golia and Viviani [15], has been neglected. The similarity solutions of the Christopher and Wang [13] problem are also different from the Golia and Viviani [15] problem. The problem of Christopher and Wang [13] has been extended by several researchers such as Al-Mudhaf and Chamkha [24] where they have presented the similarity solutions for MHD Marangoni convection in the presence of heat generation or absorption effects and Magyari and Chamkha [25] reported the exact analytical solutions of thermosolutal Marangoni flows in the presence of temperature-dependent volumetric heat source/sinks as well as of a first-order chemical reaction. Recently, Hamid et al. [26] studied the two-dimensional Marangoni convection flow past a flat plate in the presence of thermal radiation, suction, and injection effects. Further MHD thermosolutal Marangoni convection boundary layer over a flat surface considering the effects of the thermal diffusion and diffusion-thermo with fluid suction and injection has been examined by Hamid et al. [27].

It should be highlighted that the present paper presents a similarity solution for the steady Marangoni convection boundary layer flow over a static semi-infinite flat plate due to an imposed temperature gradient in a nanofluid, which extends the problem by Christopher and Wang [13] to the case of nanofluid. The nanofluid equations model proposed by Tiwari and Das [20] has been used. This model has been very successfully used in several papers [21, 28-32]. Thus, we wish to highlight that this present study is original and all the results are new. To the best of our knowledge, the present problem has not been considered before. The study of nanofluid is still at its early stage and it seems difficult to have a precise idea on the way the use of nanoparticles acts in heat transfer. A clear picture on the boundary layer flows of nanofluid is yet to emerge.

\section{Problem Formulation}

We consider the steady two-dimensional boundary layer flow past a semi-infinite flat plate in a water-based nanofluid containing different types of nanoparticles, namely, copper $(\mathrm{Cu})$, alumina $\left(\mathrm{Al}_{2} \mathrm{O}_{3}\right)$, and titania $\left(\mathrm{TiO}_{2}\right)$, with Marangoni effects. The nanofluid is assumed incompressible and the flow is assumed to be laminar. It is also assumed that the base fluid (i.e., water) and the nanoparticles are in thermal equilibrium and no slip occurs between them. The thermophysical properties of the nanofluids are given in Table 1 (see Oztop and Abu-Nada [29]). Further, we consider a Cartesian coordinate system $(x, y)$, where $x$ and $y$ are the coordinates measured along the plate and normal to it, respectively, and the flow takes place at $y \geq 0$. It is also assumed that the temperature of the plate is $T_{w}(x)$ and that of the ambient nanofluid is $T_{\infty}$. Following $[15-17,25,33,34]$ the surface tension $\sigma$ is assumed to vary linearly with temperature as follow:

$$
\sigma=\sigma_{0}\left[1-\gamma\left(T-T_{0}\right)\right]
$$

where $\sigma_{0}$ and $T_{0}$ are the characteristics surface tension and temperature, respectively, and we assume that $T_{0} \equiv T_{\infty}$. Equation (1) is a commonly made assumption [34]. For most liquids, the surface tension decreases with temperature; that is, $\gamma$ is a positive fluid property.

The steady boundary layer equations for a nanofluid in the coordinates $\bar{x}$ and $\bar{y}$ are $([13,20])$

$$
\begin{gathered}
\frac{\partial u}{\partial x}+\frac{\partial v}{\partial y}=0 \\
u \frac{\partial u}{\partial x}+v \frac{\partial u}{\partial y}=\frac{\mu_{\mathrm{nf}}}{\rho_{\mathrm{nf}}} \frac{\partial^{2} u}{\partial y^{2}} \\
u \frac{\partial T}{\partial x}+v \frac{\partial T}{\partial y}=\alpha_{\mathrm{nf}} \frac{\partial^{2} T}{\partial y^{2}}
\end{gathered}
$$

subject to the boundary conditions

$$
\begin{gathered}
v=0, \quad T=T_{0}+A x^{m+1}, \quad \mu_{\mathrm{nf}} \frac{\partial u}{\partial y}=\frac{\partial \sigma}{\partial T} \frac{\partial T}{\partial x} \quad \text { at } y=0, \\
u=0, \quad T=T_{\infty} \quad \text { as } y \longrightarrow \infty .
\end{gathered}
$$

Here, $u$ and $v$ are the velocity components along the $x$ - and $y$-axes, respectively, $T$ is the temperature of the nanofluid, $m$ is the constant exponent of the temperature, $\alpha_{\mathrm{nf}}$ is the thermal diffusivity of the nanofluid, $\rho_{\mathrm{nf}}$ is the effective density of the nanofluid, $k_{\mathrm{nf}}$ is the effective thermal conductivity of the nanofluid, and $\mu_{\mathrm{nf}}$ is the effective viscosity of the nanofluid, which are given by

$$
\begin{gathered}
\alpha_{\mathrm{nf}}=\frac{k_{\mathrm{nf}}}{\left(\rho C_{p}\right)_{\mathrm{nf}}}, \quad \rho_{\mathrm{nf}}=(1-\phi) \rho_{f}+\phi \rho_{s}, \\
\mu_{\mathrm{nf}}=\frac{\mu_{f}}{(1-\phi)^{2.5}}, \quad\left(\rho C_{p}\right)_{\mathrm{nf}}=(1-\phi)\left(\rho C_{p}\right)_{f}+\phi\left(\rho C_{p}\right)_{s} \\
\frac{k_{\mathrm{nf}}}{k_{f}}=\frac{\left(k_{s}+2 k_{f}\right)-2 \phi\left(k_{f}-k_{s}\right)}{\left(k_{s}+2 k_{f}\right)+\phi\left(k_{f}-k_{s}\right)},
\end{gathered}
$$

where $\phi$ is the nanoparticle volume fraction, $\rho_{f}$ is the reference density of the fluid fraction, $\rho_{s}$ is the reference 
velocity of the solid fraction, $\mu_{f}$ is the viscosity of the fluid fraction, $k_{f}$ is the thermal conductivity of the fluid, $k_{s}$ is the thermal conductivity of the solid, and $\left(\rho C_{p}\right)_{\mathrm{nf}}$ is the heat capacity of the nanofluid.

We look now for a similarity solution of (2)-(4) subject to the boundary conditions (5) of the following form:

$$
\begin{gathered}
\psi=C_{1} x^{(2+m) / 3} f(\eta), \quad \theta(\eta)=\frac{T-T_{\infty}}{A x^{1+m}}, \\
\eta=C_{2} x^{(m-1) / 3} y,
\end{gathered}
$$

where $\psi$ is the stream function which is defined as $u=\partial \psi / \partial y$ and $v=-\partial \psi / \partial x$. Further, $m, A, C_{1}$, and $C_{2}$ are constants with $A, C_{1}$, and $C_{2}$ given by

$$
\begin{gathered}
A=\frac{\Delta T}{L^{m+1}}, \quad C_{1}=\sqrt[3]{\frac{\sigma_{0} \gamma A \mu_{f}}{\rho_{f}^{2}}}, \\
C_{2}=\sqrt[3]{\frac{\sigma_{0} \gamma A \rho_{f}}{\mu_{f}^{2}}},
\end{gathered}
$$

with $L$ being the length of the surface and $\Delta T$ being the constant characteristic temperature. Substituting (7) into (2) and (3), we get the following ordinary differential equations:

$$
\begin{aligned}
& \frac{1}{(1-\phi)^{2.5}\left(1-\phi+\phi \rho_{s} / \rho_{f}\right)} f^{\prime \prime \prime}+\frac{2+m}{3} f f^{\prime \prime} \\
& -\frac{1+2 m}{3} f^{\prime 2}=0, \\
& \frac{1}{\operatorname{Pr}} \frac{k_{\mathrm{nf}} / k_{f}}{\left(1-\phi+\phi\left(\rho C_{p}\right)_{s} /\left(\rho C_{p}\right)_{f}\right)} \theta^{\prime \prime}+\frac{2+m}{3} f \theta \\
& -(1+m) f^{\prime} \theta=0,
\end{aligned}
$$

and the boundary conditions (5) become

$$
\begin{gathered}
f(0)=0, \quad \frac{1}{(1-\phi)^{2.5}} f^{\prime \prime}(0)=-1, \quad \theta(0)=1, \\
f^{\prime}(\infty)=0, \quad \theta(\infty)=0 .
\end{gathered}
$$

We can now determine the surface velocity $u(x, 0)=u_{w}(x)$ as

$$
u_{w}(x)=\sqrt[3]{\frac{\left(\sigma_{0} \gamma A\right)^{2}}{\rho_{f} \mu_{f}}} x^{(1+2 m) / 3} f^{\prime}(0) .
$$

A quantity of interest is the local Nusselt number $\mathrm{Nu}_{x}$ which is defined as

$$
\mathrm{Nu}_{x}=\frac{x q_{w}(x)}{k_{f}[T(x, 0)-T(x, \infty)]},
$$

where $q_{w}(x)$ is the heat flux from the surface of the plate and it is given by

$$
q_{w}(x)=-k_{\mathrm{nf}}\left(\frac{\partial T}{\partial y}\right)_{y=0} .
$$

Using (7), (12), and (13), we get

$$
\mathrm{Nu}_{x}=-\frac{k_{\mathrm{nf}}}{k_{f}} C_{2} x^{(2+m) / 3} \theta^{\prime}(0) .
$$

The average Nusselt number $\mathrm{Nu}_{L}$ based on the average temperature difference between the temperature of the surface and the temperature far from the surface (ambient fluid) is given by

$$
\mathrm{Nu}_{L}=-\frac{6+3 m}{5+4 m} \frac{k_{\mathrm{nf}}}{k_{f}} \mathrm{Ma}_{L}^{1 / 3} \operatorname{Pr}^{-1 / 3} \theta^{\prime}(0),
$$

where $\mathrm{Ma}_{L}$ is the Marangoni based on $L$ and is defined as

$$
\mathrm{Ma}_{L}=\frac{\sigma_{T} A L^{2+m}}{\mu_{f} \alpha_{f}}=\frac{\sigma_{T} \Delta T L}{\mu_{f} \alpha_{f}} .
$$

Also, the total mass flow $\dot{m}$ in the boundary layer per unit width is given by

$$
\dot{m}=\int_{0}^{\infty} \rho_{f} u d y=\sqrt[3]{\sigma_{0} \gamma \rho_{f} \mu_{f}} x^{(2+m) / 3} f(\infty) .
$$

\section{Results and Discussion}

The nonlinear ordinary differential equation (9) subject to the boundary conditions (10) forms a two-point boundary value problem (BVP) and is solved numerically using the Runge-Kutta-Fehlberg fourth-fifth-order (RKF45) method using Maple 12- and the algorithm RKF45 in Maple has been well tested for its accuracy and robustness [35]. In this method, it is most important to choose the appropriate finite value of the edge of boundary layer, $\eta \rightarrow \infty$ (say $\eta_{\infty}$ ) that is between 4 and 10, which is in accordance with the standard practice in the boundary layer analysis. We begin with some initial guess value of $\eta_{\infty}$ and solve (9) subject to the boundary conditions (10) with some particular set of parameters to obtain the surface velocity $f^{\prime}(0)$ and the temperature gradient $-\theta^{\prime}(0)$. The solution process is repeated until further changes (increment) in $\eta_{\infty}$ would not lead to any changes in the values of $f^{\prime}(0)$ and $-\theta^{\prime}(0)$, or in other words, the results are independent of the value of $\eta_{\infty}$. The initial step size employed is $h=\Delta \eta=0.1$. Following Oztop and Abu-Nada [29], we considered the range of nanoparticles volume fraction $\phi$ as $0 \leq \phi \leq 0.2$. The Prandtl number of the base fluid (water) is kept constant at 6.2. Further, it should also be pointed out that the thermophysical properties of fluid and nanoparticles $(\mathrm{Cu}$, $\mathrm{Al}_{2} \mathrm{O}_{3}$, and $\mathrm{TiO}_{2}$ ) used in this study are given in Table 1 . It is worth mentioning that, the present study reduces to that of a classical viscous (regular) fluid studied by Christopher and Wang [13] when $\phi=0$.

Figures 1 and 2 show the distribution of the dimensionless velocity $f^{\prime}(\eta)$ and temperature $\theta(\eta)$ profiles for the three types of the nanoparticles considered when the solid volume fraction of the nanofluid parameter $\phi=0.1$ and $m=0$ (which corresponds to a linear variation of the surface temperature with the distance $x$ measured along the flat plate), while Figures 3 and 4 display the variation with $\phi$ of the reduced 
TABLE 1: Thermophysical properties of fluid and nanoparticles [29].

\begin{tabular}{lcccc}
\hline Physical properties & Fluid phase (water) & $\mathrm{Cu}$ & $\mathrm{Al}_{2} \mathrm{O}_{3}$ & $\mathrm{TiO}_{2}$ \\
\hline$C_{p}(\mathrm{~J} / \mathrm{kg} \mathrm{K})$ & 4179 & 385 & 765 & 686.2 \\
$\rho\left(\mathrm{kg} / \mathrm{m}^{3}\right)$ & 997.1 & 8933 & 3970 & 4250 \\
$k(\mathrm{~W} / \mathrm{mK})$ & 0.613 & 400 & 40 & 8.9538
\end{tabular}

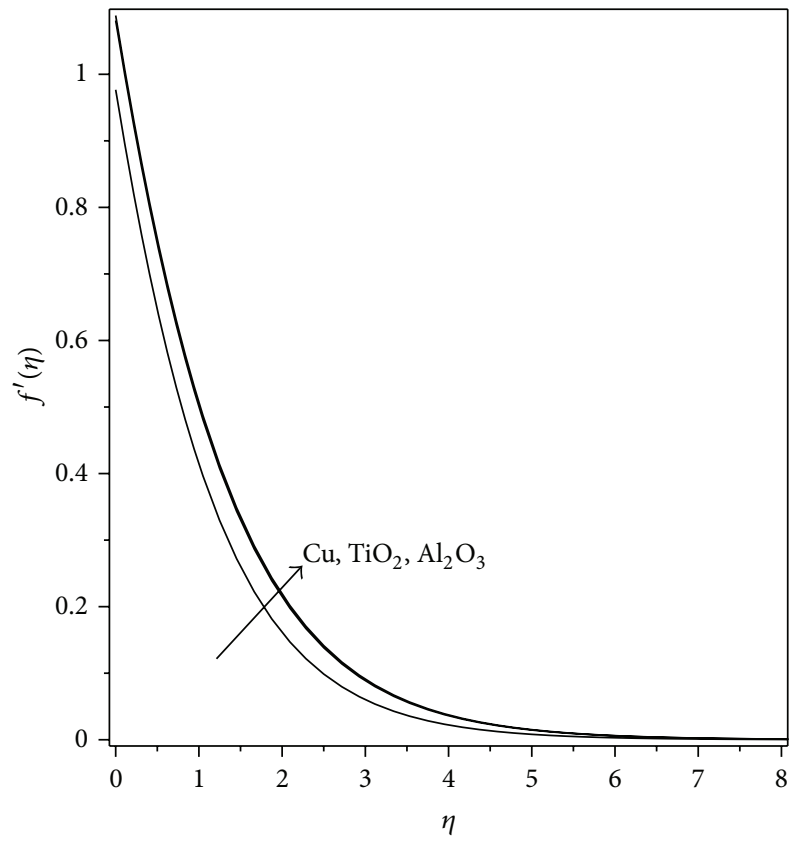

FIGURE 1: Dimensionless velocity profiles $f^{\prime}(\eta)$ for different types of nanoparticles when $\phi=0.1$ and $m=0$.

surface velocity, $f^{\prime}(0)$, and reduced temperature gradient, $-\theta^{\prime}(0)$, respectively. It is seen from Figure 1 that the velocity profiles in Figure 1 for $\mathrm{Al}_{2} \mathrm{O}_{3}$ and $\mathrm{TiO}_{2}$ are almost identical while the profile for $\mathrm{Cu}$ is smaller. This is consistent with the variation of the reduced surface velocity $f^{\prime}(0)$ as shown in Figure 3. In Figure 2, it is shown that the temperature profile is the highest for higher thermal diffusivity nanoparticle $(\mathrm{Cu})$. On the other hand, the thermal boundary layer thickness as shown in Figure 2 decreases with a decrease in thermal diffusivity, which in turn gives rise to the $-\theta^{\prime}(0)$ as illustrated in Figure 4. Figures 3 and 4 display the surface velocity, $f^{\prime}(0)$, and the surface temperature gradient, $-\theta^{\prime}(0)$, respectively, for different types of nanoparticles $\left(\mathrm{Cu}, \mathrm{Al}_{2} \mathrm{O}_{3}\right.$, and $\left.\mathrm{TiO}_{2}\right)$ when $m=0$. One can see that the surface velocity, $f^{\prime}(0)$ and the surface temperature gradient, $-\theta^{\prime}(0)$ decrease as $\phi$ increases for all three nanoparticles $\left(\mathrm{Cu}, \mathrm{Al}_{2} \mathrm{O}_{3}, \mathrm{TiO}_{2}\right)$. It should be noticed that the entire values of $-\theta^{\prime}(0)$ are always positive; that is, the heat is transferred from hot surface to the cold surface. In Figure 4, we are looking at the variation of temperature gradient with the nanoparticle volume fraction $\phi$. It is observed that the reduced value of thermal diffusivity leads to higher temperature gradients and, therefore, higher enhancements in heat transfer. Nanoparticles with low thermal diffusivity, $\mathrm{TiO}_{2}$, have better enhancement on heat transfer compared to $\mathrm{Cu}$ and $\mathrm{Al}_{2} \mathrm{O}_{3}$. Further, Figure 5 shows the variations of the reduced surface velocity $f^{\prime}(0)$ with $m$,

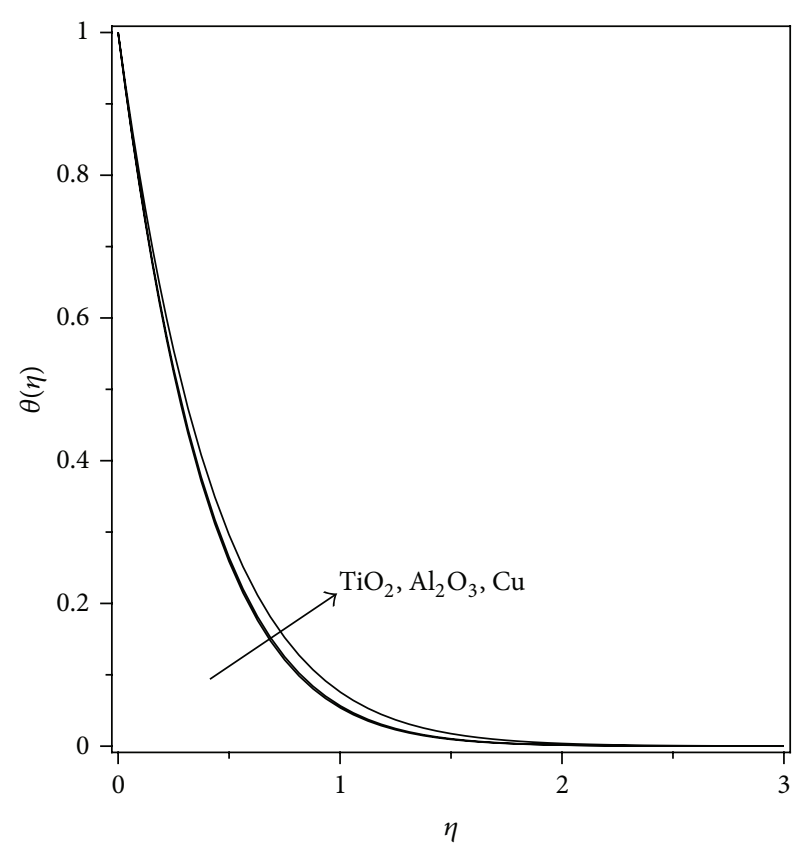

Figure 2: Dimensionless temperature profiles $\theta(\eta)$ for different types of nanoparticles when $\phi=0.1$ and $m=0$.

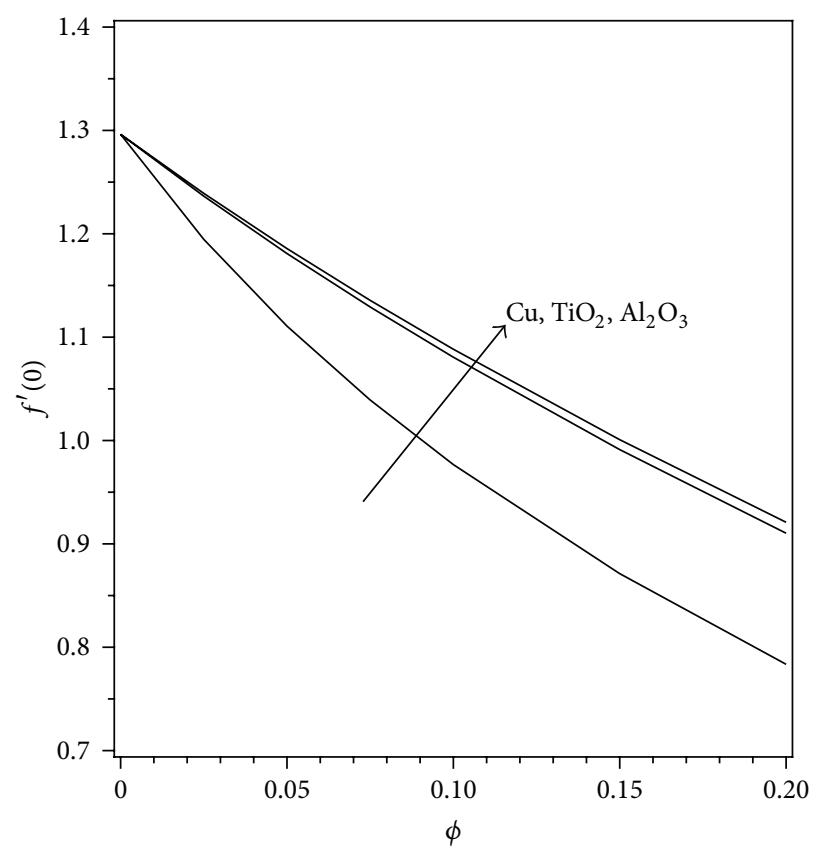

FIgURE 3: Variation of surface velocity $f^{\prime}(0)$ with $\phi$ for different types of nanoparticles when $\operatorname{Pr}=6.2$ and $m=0$.

where $m=0$ refers to a linear variation of the surface temperature with the distance $x$ measured along the flat plate and $m=1$ is a quadratic variation of the surface temperature with $x$, while $m=-0.5$ refers to a temperature variation relative to the square root of $x$. It should also be noticed that for $\phi=0$ (regular fluid), we reproduced the variations of surface velocity obtained by Christopher and Wang [13] as illustrated by dashed lines in the figure. 


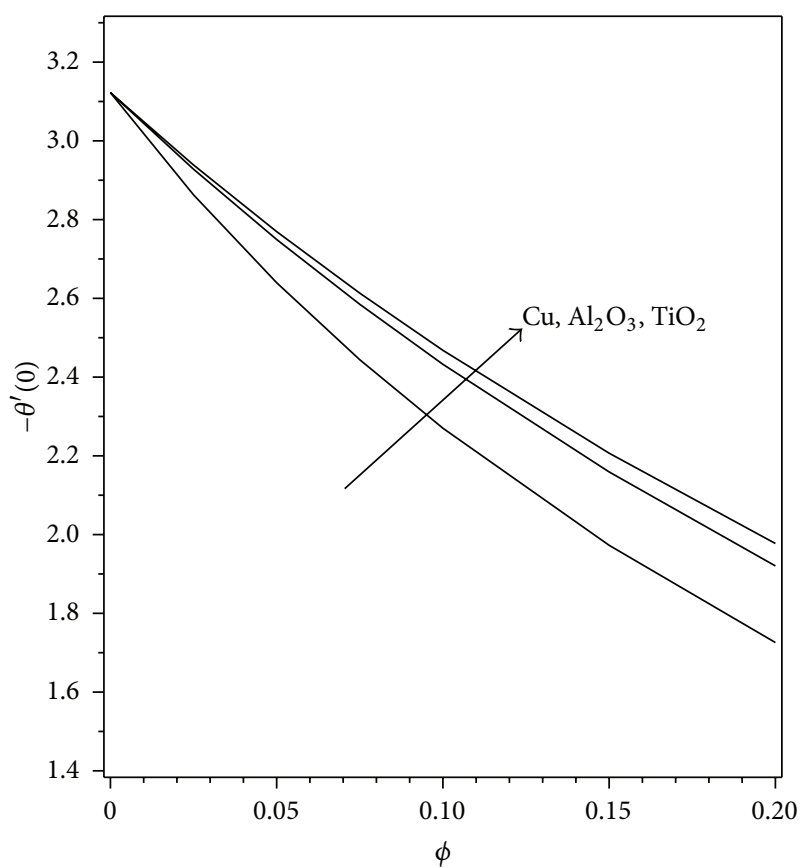

FIgURE 4: Variation of $-\theta^{\prime}(0)$ with $\phi$ for different types of nanoparticles when $\operatorname{Pr}=6.2$ and $m=0$.

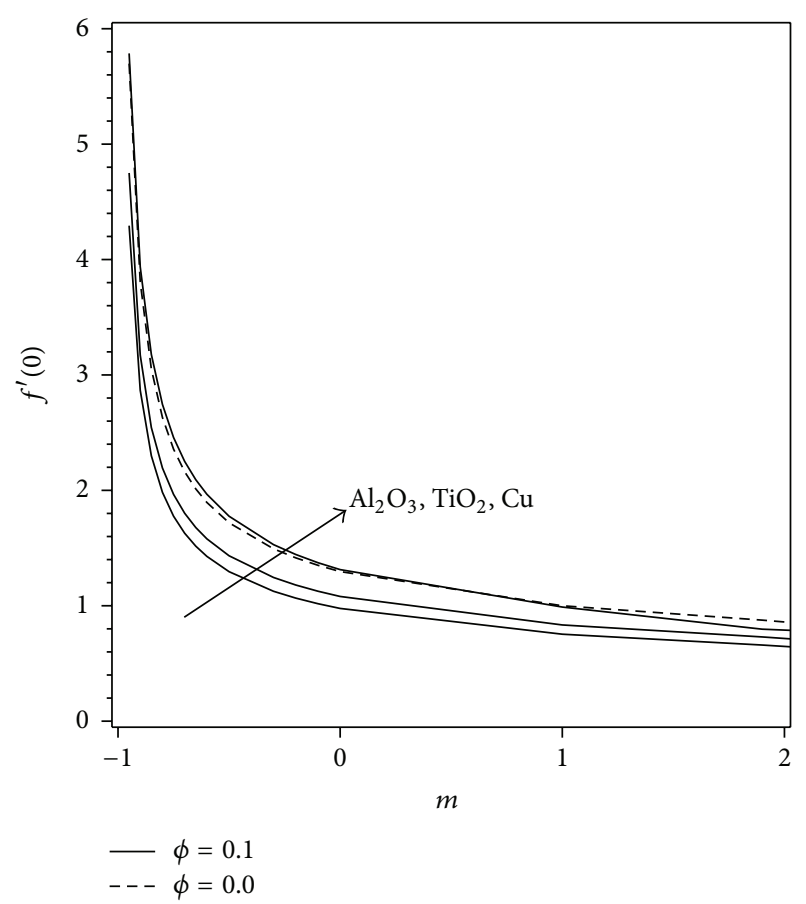

Figure 5: Variation of surface velocity $f^{\prime}(0)$ with $m$ for different types of nanoparticles when $\operatorname{Pr}=6.2, \phi=0$ (regular fluid), and $\phi=0.1$.

Figures 6 to 11 show the dimensionless velocity $f^{\prime}(\eta)$ and temperature $\theta(\eta)$ profiles for different values of $\phi$ in the range $0 \leq \phi \leq 0.2$ when $m=0$ with different types of nanoparticles, namely, $\mathrm{Cu}, \mathrm{Al}_{2} \mathrm{O}_{3}$, and $\mathrm{TiO}_{2}$, respectively. It is worth mentioning that nanoparticle volume fraction is a key parameter for studying the effect of nanoparticles on flow fields and

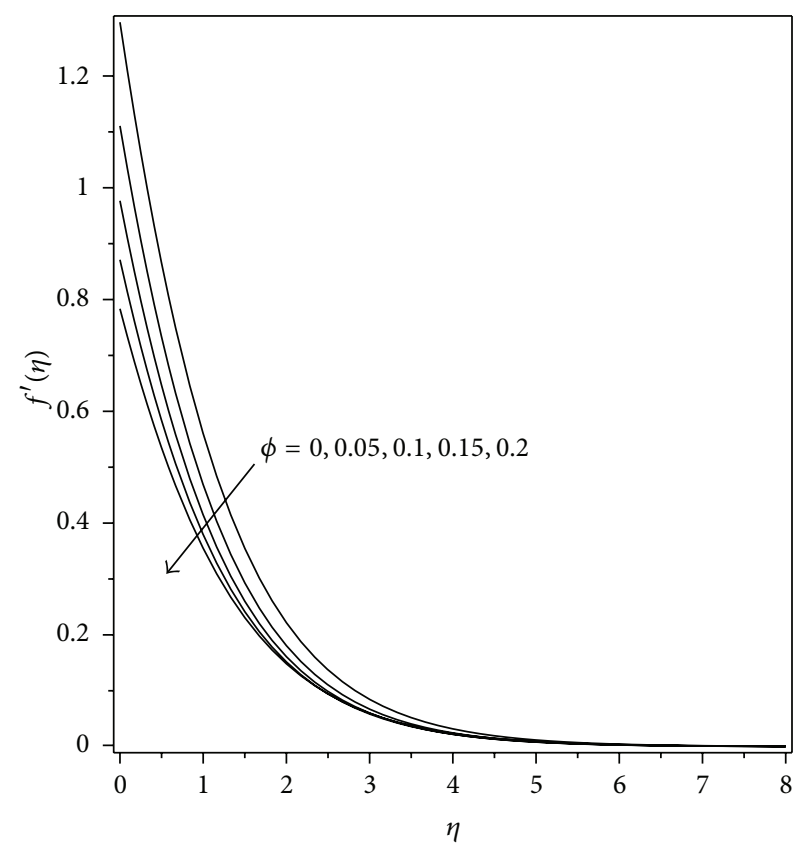

FIGURE 6: Dimensionless velocity profiles $f^{\prime}(\eta)$ for $\mathrm{Cu}$ nanoparticles with $m=0$ and various values of $\phi$.

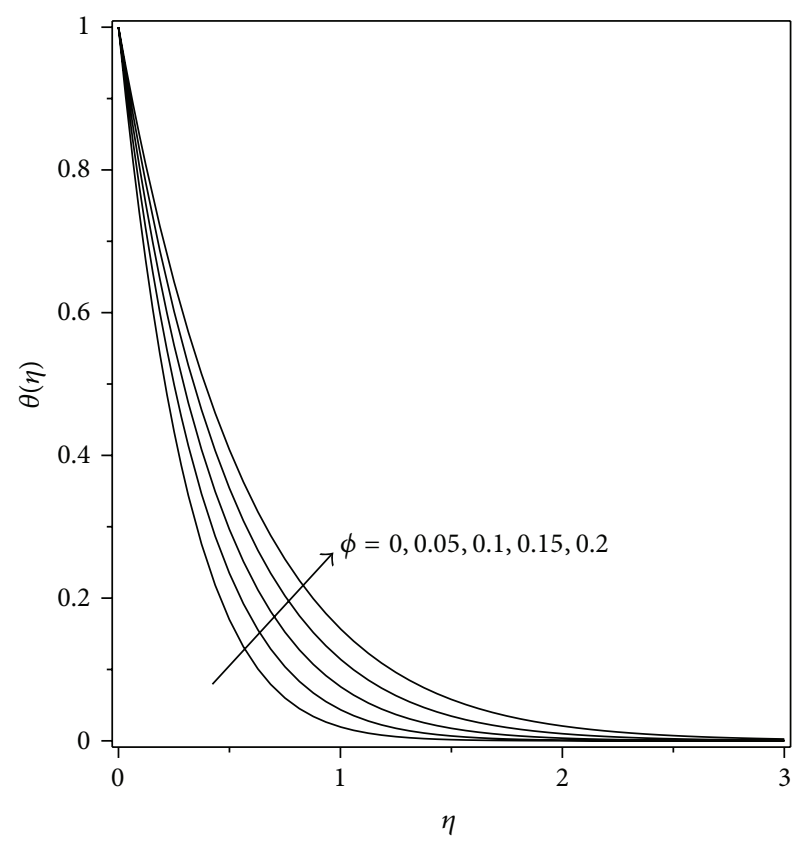

Figure 7: Dimensionless temperature profiles $\theta(\eta)$ for $\mathrm{Cu}$ nanoparticles with $m=0$ and various values of $\phi$.

temperature distributions. More fluid is heated for higher values of nanoparticle volume fraction. Flow strength also increases with increasing of nanoparticle volume fraction. As the nanoparticle volume fraction increases, movements of particles become irregular and random due to increasing of energy exchange rates in the fluid (see [29]). It is observed from these figures that, for any type of nanoparticles, as the nanoparticle volume fraction $\phi$ increases, both the surface velocities and the temperature gradients decrease, which is 


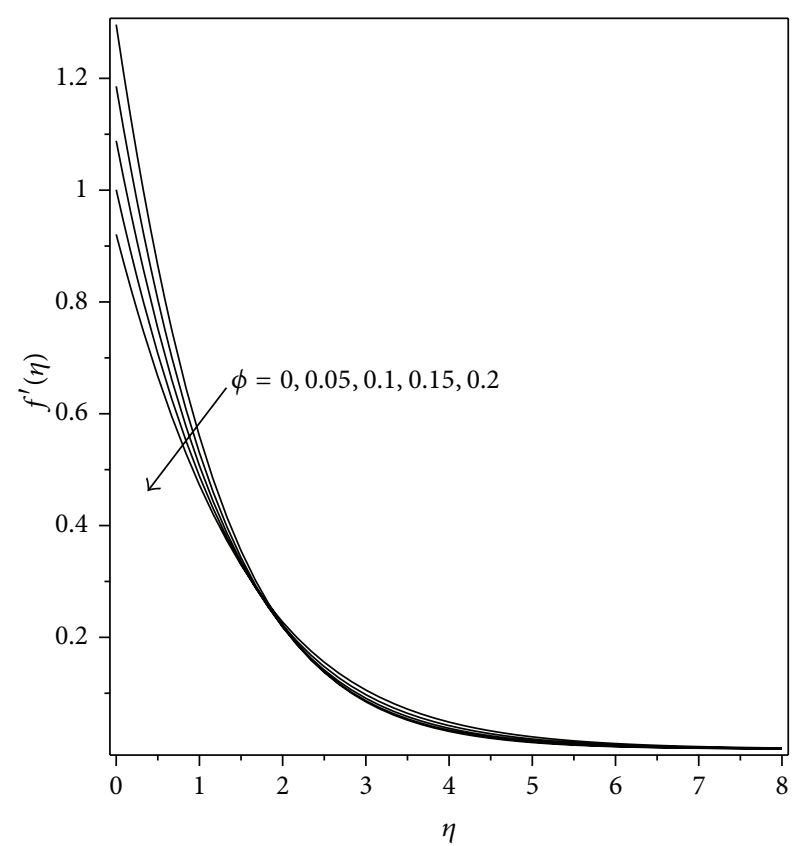

FIGURE 8: Dimensionless velocity profiles $f^{\prime}(\eta)$ for $\mathrm{Al}_{2} \mathrm{O}_{3}$ nanoparticles with $m=0$ and various values of $\phi$.

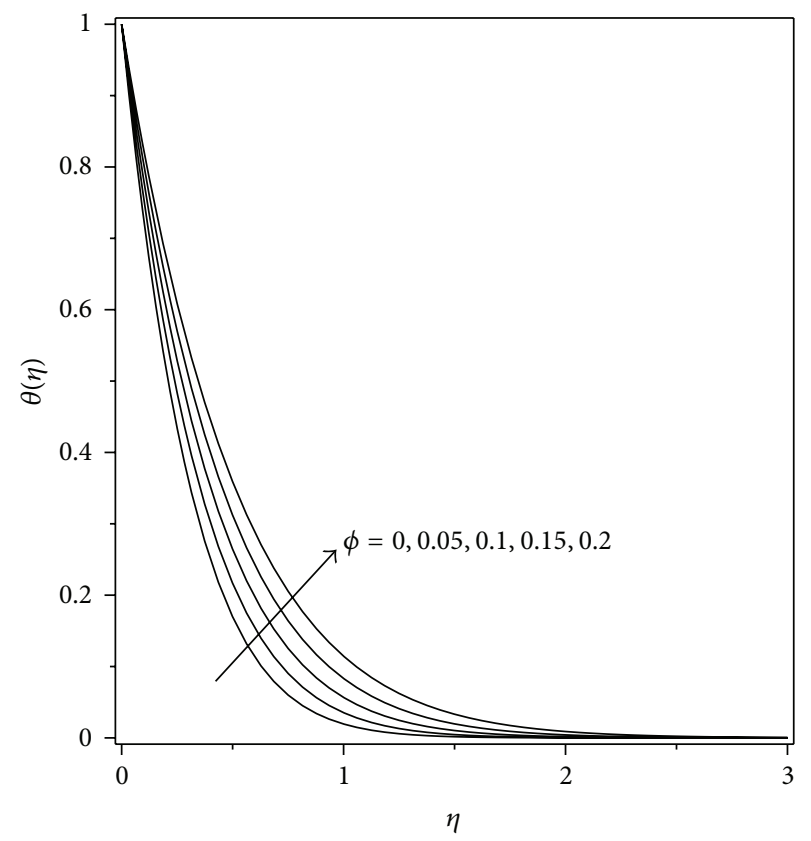

Figure 9: Dimensionless temperature profiles $\theta(\eta)$ for $\mathrm{Al}_{2} \mathrm{O}_{3}$ nanoparticles with $m=0$ and various values of $\phi$.

again in agreement with Figures 3 and 4 . It should also be noticed again, that for $\phi=0$ (regular fluid), we reproduced the velocity and temperature profiles obtained by Christopher and Wang [13].

\section{Conclusion}

We have theoretically and numerically studied the problem of steady two-dimensional laminar Marangoni-driven boundary layer flow in nanofluids. It is worth mentioning that the

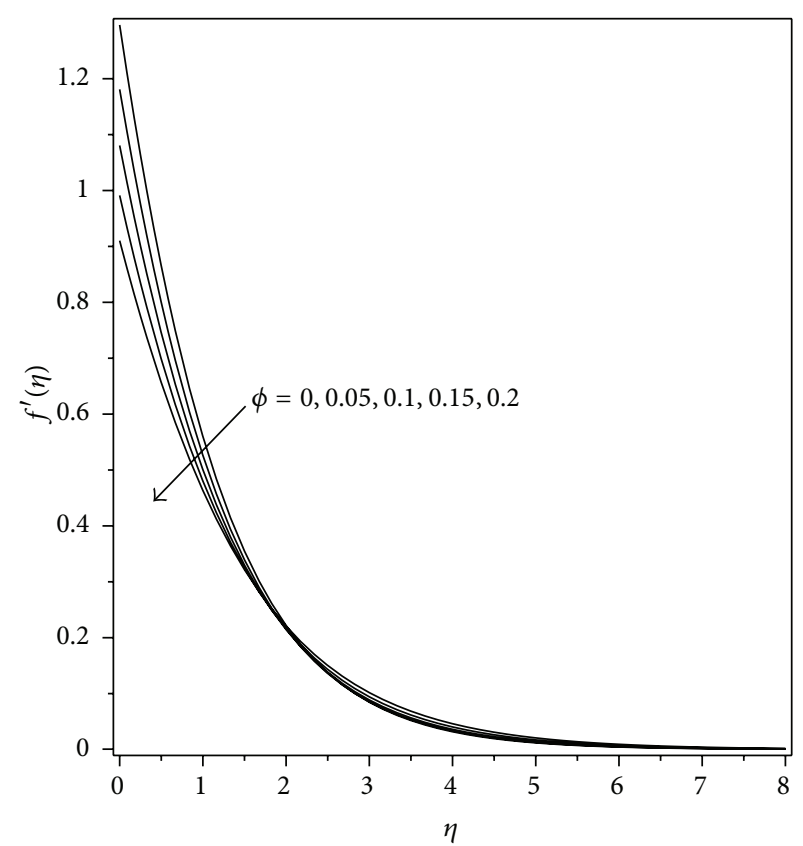

FIgURE 10: Dimensionless temperature profiles $\theta(\eta)$ for $\mathrm{TiO}_{2}$ nanoparticles with $m=0$ and various values of $\phi$.

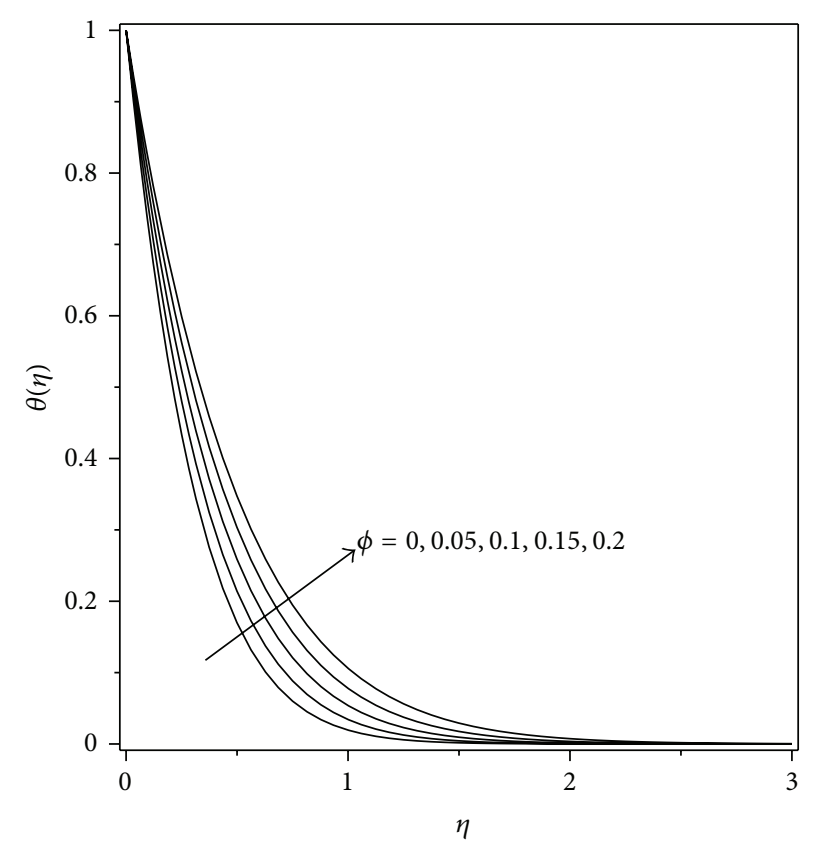

FIGURE 11: Dimensionless velocity profiles $f^{\prime}(\eta)$ for $\mathrm{TiO}_{2}$ nanoparticles with $m=0$ and various values of $\phi$.

novelty of the present paper is to study numerically the heat transfer in a liquid layer driven by Marangoni flow with various types of nanoparticles $\left(\mathrm{Cu}, \mathrm{Al}_{2} \mathrm{O}_{3}\right.$, and $\left.\mathrm{TiO}_{2}\right)$ in the base fluid which has not been considered before. The nonlinear ordinary differential equation (9) subject to the boundary conditions (10) forms a two-point boundary value problem (BVP) and is solved numerically using the Runge-KuttaFehlberg fourth-fifth-order (RKF45) method using Maple 12, 
and the algorithm RKF45 in Maple has been well tested for its accuracy and robustness. Similarity solutions are obtained for the surface velocity $f^{\prime}(0)$ and the surface temperature gradient $-\theta^{\prime}(0)$ as well as the velocity and temperature profiles for some values of the governing parameters, namely, the solid volume fraction of the nanofluid $\phi(0 \leq \phi \leq 0.2)$, the constant exponent $m$, and the Prandtl number Pr. It was found that nanoparticles with low thermal diffusivity $\left(\mathrm{TiO}_{2}\right)$ have better enhancement on heat transfer compared to $\mathrm{Al}_{2} \mathrm{O}_{3}$ and $\mathrm{Cu}$.

\section{Acknowledgments}

The authors gratefully acknowledge the financial support received in the form of a FRGS Research Grant from the Ministry of Higher Education, Malaysia, and a Research University Grant (AP-2013-009) from the Universiti Kebangsaan Malaysia. They also wish to express their sincere thanks to the reviewers for the valuable comments and suggestions.

\section{References}

[1] L. Godson, B. Raja, D. M. Lal, and S. Wongwises, "Enhancement of heat transfer using nanofluids-an overview," Renewable and Sustainable Energy Reviews, vol. 14, no. 2, pp. 629-641, 2010.

[2] S. K. Das, S. U. S. Choi, W. Yu, and T. Pradeep, Nanofluids: Science and Technology, Wiley, Hoboken, NJ, USA, 2007.

[3] J. Buongiorno, "Convective transport in nanofluids," Journal of Heat Transfer, vol. 128, no. 3, pp. 240-250, 2006.

[4] W. Daungthongsuk and S. Wongwises, "A critical review of convective heat transfer of nanofluids," Renewable and Sustainable Energy Reviews, vol. 11, no. 5, pp. 797-817, 2007.

[5] V. Trisaksri and S. Wongwises, "Critical review of heat transfer characteristics of nanofluids," Renewable and Sustainable Energy Reviews, vol. 11, no. 3, pp. 512-523, 2007.

[6] X.-Q. Wang and A. S. Mujumdar, "Heat transfer characteristics of nanofluids: a review," International Journal of Thermal Sciences, vol. 46, no. 1, pp. 1-19, 2007.

[7] X.-Q. Wang and A. S. Mujumdar, "A review on nanofluids-part I: theoretical and numerical investigations," Brazilian Journal of Chemical Engineering, vol. 25, no. 4, pp. 613-630, 2008.

[8] S. Kakaç and A. Pramuanjaroenkij, "Review of convective heat transfer enhancement with nanofluids," International Journal of Heat and Mass Transfer, vol. 52, no. 13-14, pp. 3187-3196, 2009.

[9] N. Putra, W. Roetzel, and S. K. Das, "Natural convection of nano-fluids," Heat and Mass Transfer, vol. 39, no. 8-9, pp. 775784, 2003.

[10] D. Wen and Y. Ding, "Formulation of nanofluids for natural convective heat transfer applications," International Journal of Heat and Fluid Flow, vol. 26, no. 6, pp. 855-864, 2005.

[11] K. S. Hwang, J.-H. Lee, and S. P. Jang, "Buoyancy-driven heat transfer of water-based $\mathrm{Al}_{2} \mathrm{O}_{3}$ nanofluids in a rectangular cavity," International Journal of Heat and Mass Transfer, vol. 50, no. 19-20, pp. 4003-4010, 2007.

[12] X.-Q. Wang and A. S. Mujumdar, "A review on nanofluids-part II: experiments and applications," Brazilian Journal of Chemical Engineering, vol. 25, no. 4, pp. 631-648, 2008.

[13] D. M. Christopher and B. Wang, "Prandtl number effects for Marangoni convection over a flat surface," International Journal of Thermal Sciences, vol. 40, no. 6, pp. 564-570, 2001.
[14] R. Tadmor, "Marangoni flow revisited," Journal of Colloid and Interface Science, vol. 332, no. 2, pp. 451-454, 2009.

[15] C. Golia and A. Viviani, "Non isobaric boundary layers related to Marangoni flows," Meccanica, vol. 21, no. 4, pp. 200-204, 1986.

[16] I. Pop, A. Postelnicu, and T. Grosan, "Thermosolutal Marangoni forced convection boundary layers," Meccanica, vol. 36, no. 5, pp. 555-571, 2001.

[17] A. J. Chamkha, I. Pop, and H. S. Takhar, "Marangoni mixed convection boundary layer flow," Meccanica, vol. 41, no. 2, pp. 219232, 2006.

[18] R. A. Hamid, N. M. Arifin, R. Nazar, F. M. Ali, and I. Pop, "Dual Solutions on thermosolutal Marangoni forced convection boundary layer with suction and injection," Mathematical Problems in Engineering, vol. 2011, Article ID 875754, 19 pages, 2011.

[19] N. Mat, N. M. Arifin, R. Nazar, F. Ismail, and I. Pop, "Radiation effects on Marangoni convection boundary layer over a permeable surface," Meccanica, vol. 48, pp. 83-89, 2013.

[20] R. K. Tiwari and M. K. Das, "Heat transfer augmentation in a two-sided lid-driven differentially heated square cavity utilizing nanofluids," International Journal of Heat and Mass Transfer, vol. 50, no. 9-10, pp. 2002-2018, 2007.

[21] N. M. Arifin, R. Nazar, and I. Pop, "Non-Isobaric Marangoni boundary layer flow for $\mathrm{Cu}, \mathrm{Al}_{2} \mathrm{O}_{3}$ and $\mathrm{TiO}_{2}$ nanoparticles in a water based fluid," Meccanica, vol. 46, no. 4, pp. 833-843, 2011.

[22] A. Remeli, N. M. Arifin, R. Nazar, F. Ismail, and I. Pop, "Marangoni-driven boundary layer flow in a nanofluid with suction and injection," World Applied Sciences Journal, vol. 17, pp. 21-26, 2012.

[23] N. A. A. Mat, N. M. Arifin, R. Nazar, and F. Ismail, "Radiation effect on Marangoni convection boundary layer flow of a nanofluid," Mathematical Sciences, vol. 6, article 21, 2012.

[24] A. Al-Mudhaf and A. J. Chamkha, "Similarity solutions for MHD thermosolutal Marangoni convection over a flat surface in the presence of heat generation or absorption effects," Heat and Mass Transfer, vol. 42, no. 2, pp. 112-121, 2005.

[25] E. Magyari and A. J. Chamkha, "Exact analytical results for the thermosolutal MHD Marangoni boundary layers," International Journal of Thermal Sciences, vol. 47, no. 7, pp. 848-857, 2008.

[26] R. A. Hamid, N. M. Arifin, R. Nazar, and F. M. Ali, "Radiation effects on Marangoni convection over a flat surface with suction and injection," Malaysian Journal of Mathematical Sciences, vol. 5, no. 1, pp. 13-25, 2011.

[27] R. A. Hamid, W. M. K. A. W. Zaimi, N. M. Arifin, N. A. A. Bakar, and B. Bidin, "Thermal-diffusion and diffusion-thermo effects on MHD thermosolutal Marangoni convection boundary layer flow over a permeable surface," Journal of Applied Mathematics, vol. 2012, Article ID 750939, 14 pages, 2012.

[28] E. Abu-Nada, "Application of nanofluids for heat transfer enhancement of separated flows encountered in a backward facing step," International Journal of Heat and Fluid Flow, vol. 29, no. 1, pp. 242-249, 2008.

[29] H. F. Oztop and E. Abu-Nada, "Numerical study of natural convection in partially heated rectangular enclosures filled with nanofluids," International Journal of Heat and Fluid Flow, vol. 29, no. 5, pp. 1326-1336, 2008.

[30] E. Abu-Nada and H. F. Oztop, "Effects of inclination angle on natural convection in enclosures filled with $\mathrm{Cu}$-water nanofluid," International Journal of Heat and Fluid Flow, vol. 30, no. 4, pp. 669-678, 2009. 
[31] M. Muthtamilselvan, P. Kandaswamy, and J. Lee, "Heat transfer enhancement of copper-water nanofluids in a lid-driven enclosure," Communications in Nonlinear Science and Numerical Simulation, vol. 15, no. 6, pp. 1501-1510, 2010.

[32] N. Bachok, A. Ishak, R. Nazar, and N. Senu, "Stagnation-point flow over a permeable stretching/shrinking sheet in a copperwater nanofluid," Boundary Value Problems, vol. 2013, article 39, 2013.

[33] C. Golia and A. Viviani, "Marangoni buoyant boundary layers," Aerotecnica Missili e Spazio, vol. 64, pp. 29-35, 1985.

[34] B. S. Dandapat, B. Santra, and H. I. Andersson, "Thermocapillarity in a liquid film on an unsteady stretching surface," International Journal of Heat and Mass Transfer, vol. 46, no. 16, pp. 3009-3015, 2003.

[35] A. Aziz, "A similarity solution for laminar thermal boundary layer over a flat plate with a convective surface boundary condition," Communications in Nonlinear Science and Numerical Simulation, vol. 14, no. 4, pp. 1064-1068, 2009. 


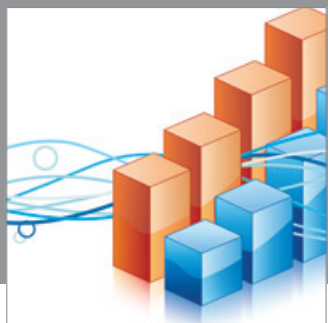

Advances in

Operations Research

mansans

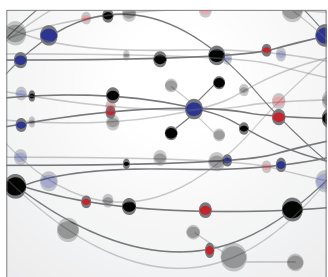

The Scientific World Journal
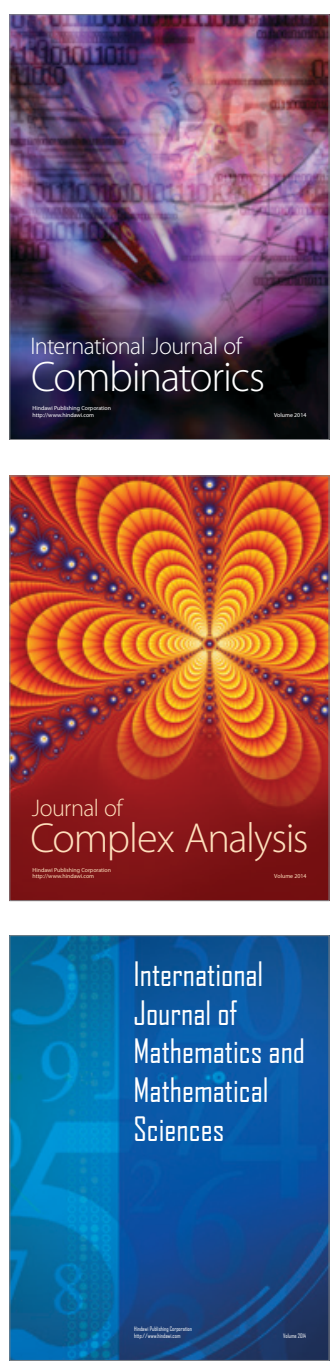
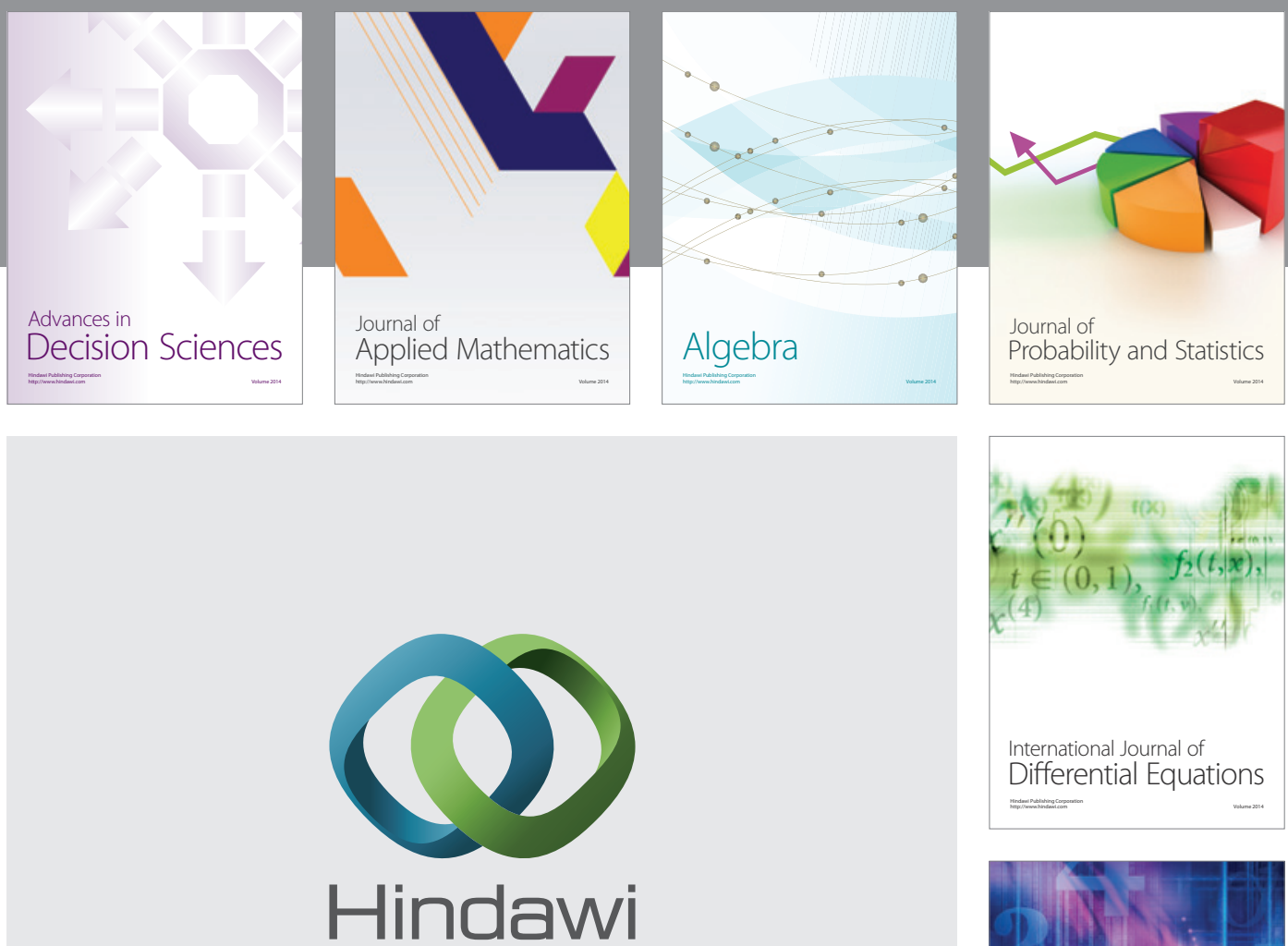

Submit your manuscripts at http://www.hindawi.com
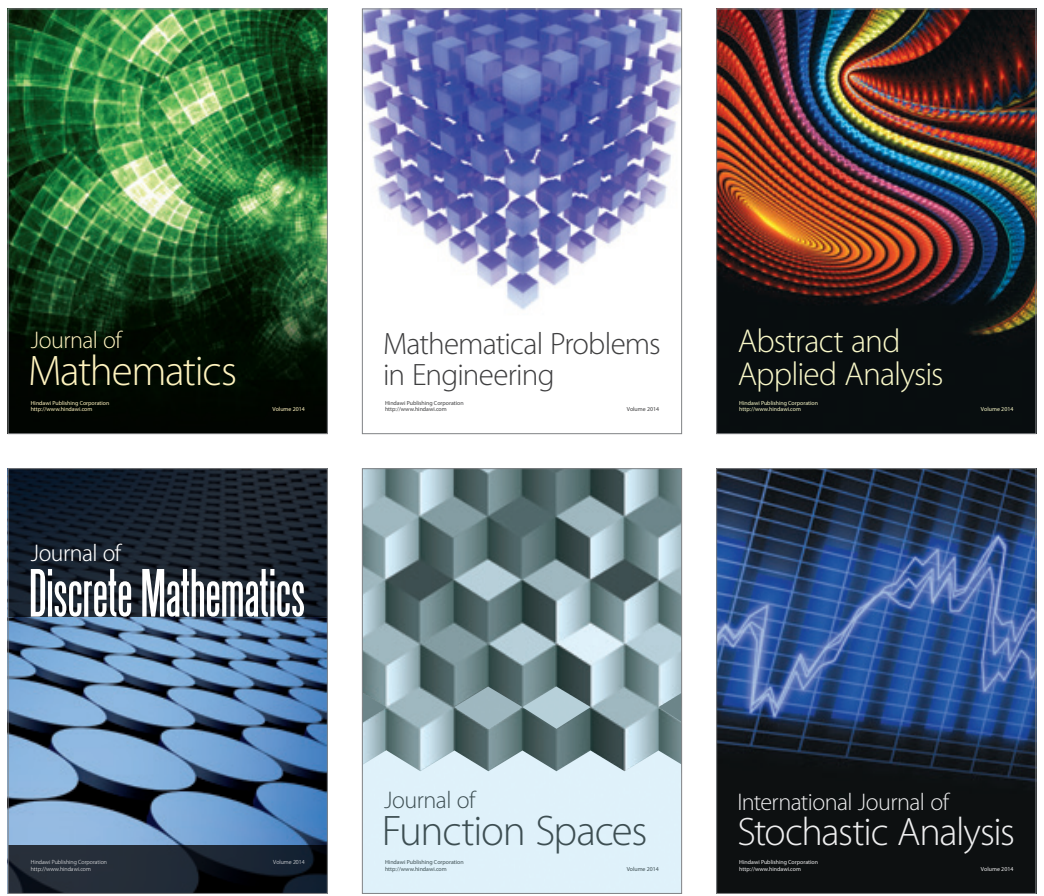

Journal of

Function Spaces

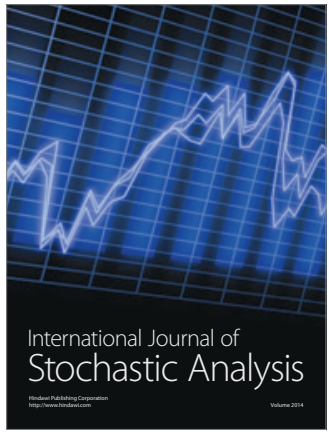

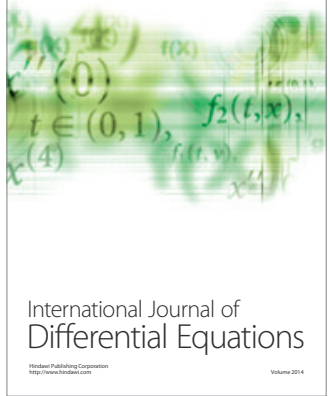
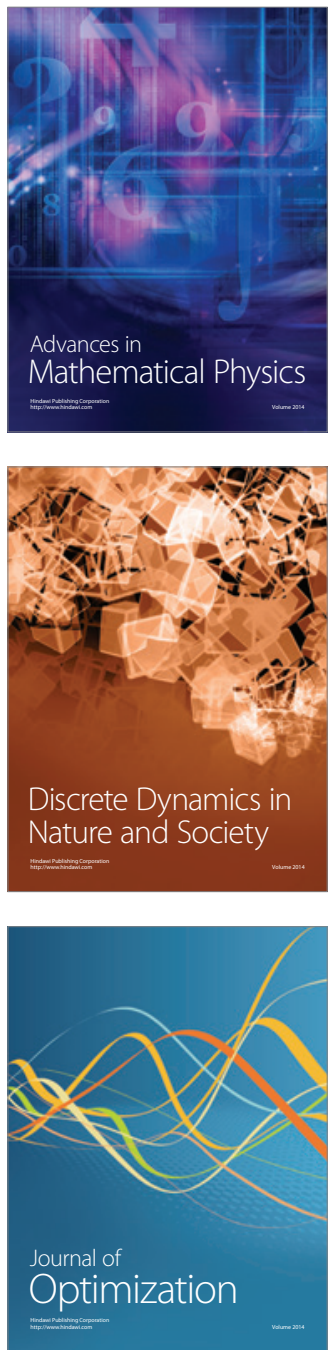